\title{
Cdk5: An Emerging Kinase in Pain Signaling
}

Tej Kumar Pareek*, Lisa Zipp and John J Letterio

Department of Pediatrics, Division of Pediatric Hematology and Oncology, University Hospitals Case Medical Center, Case Western Reserve University, Cleveland, OH 44106, USA

\begin{abstract}
Pain is an important survival mechanism for an organism. It can turn into severe mental and physical disorder however, if the molecular and/or cellular pathways involved in pain signaling are altered. Chronic pain is characterized by an altered pain perception that includes allodynia (a response to a normally non-noxious stimulus) and hyperalgesia (an exaggerated response to a normally noxious stimulus). Past few years of pain research has been mainly focused on precise understanding of the molecular and cellular nociceptive signatures altered during chronic pain, so that more effective pain relievers can be developed. The importance of protein kinases in normal cellular homeostasis and disease pathogenesis has evolved rapidly in the past few decades. The recent advancement defining the role of multiple protein kinases in regulating neuronal plasticity and pain sensitization has gained enough attention of pharmaceutical industry to develop specific and selective kinase inhibitors as analgesics. Cyclin-dependent kinase 5 (Cdk5) is one such emerging kinase in pain biology. We will discuss here the recent advancement and therapeutic potential of Cdk5 in pain signaling.
\end{abstract}

\section{Introduction}

Pain is both a highly important health problem and an increasingly mature topic of study. Over one-third of the world's population suffers from persistent or recurrent pain. To an estimate chronic pain affects approximately 116 million American adults alone, more than the total affected by heart disease, cancer, and diabetes combined. Medical conditions including diabetes, AIDS, and multiple sclerosis all have a high incidence of chronic neuropathic pain. Because pain impairs one's ability to carry out a productive life, it has serious economic consequences in addition to being a major health problem. Pain alone costs the nation up to $\$ 635$ billion each year in medical treatment and lost productivity [1]. It is important to note that despite this mind boggling statistics only $<2 \%$ of the NIH budget goes to fund pain research. Thus, the 2010 Patient Protection and Affordable Care Act required the Department of Health and Human Services (HHS) to enlist the Institute of Medicine (IOM) in examining pain as a public health problem. The idea of pain is not new to us and a notable information regarding pain has emerged since $18^{\text {th }}$ century [2]. Since then, scientists have made remarkable strides to understand the biological, cognitive, and psychological underpinnings of pain. However, despite much work and thought, fundamental issues about pain remain unresolved. Notably, these include whether pain results from the activity of a dedicated neural apparatus or is the product of less specific processes. An important focus of pain research has been the study of chronic pain mechanisms, particularly the processes that lead to the spontaneous pain and hyperalgesia associated with these states. The use of currently available pain medication and therapies is limited partly due to their deleterious side effects and inadequate efficacy. For example, morphine and its analogues are the most effective analgesics for treating severe and terminal pain but they are frequently under-prescribed because of the fear that, as tolerance to the drug develops, dependence and addiction will follow. Therefore, it's quite evident that still many gaps persist, and developing more effective and less risky pain relievers remains a major challenge.

To the excitement of pain biologists, the last few decades have been an incredibly productive time in pain research. Information from recent scientific discoveries is virtually exploding and has revealed numerous novel targets for the advent of new pain therapies. Major advances have occurred at levels spanning from molecular studies that have identified transduction proteins in nociceptors to cortical imaging studies which reveal how pain is experienced on a cognitive level $[3,4]$. Cellular networks involved in perceiving pain transduction and perception complexly involve fundamental biological events at multiple levels of the nervous system. Nociceptors are the first fundamental unit of this cellular network. This subpopulation of primary sensory neurons is activated by different noxious stimuli such as heat, cold, chemical sensation, mechanical sensation, inflammation, etc. Identification of cellular and molecular targets that are altered on specific populations of nociceptors during different types of pain have helped in the development of novel pain therapies that target specific mechanisms on identified populations of nociceptors. Elegant molecular genetic studies conducted in the past few years have now enabled us to identify specific molecules that are involved in the processes of pain transduction. Recently, David Julius group has discussed about these cellular and molecular nociceptive signatures at length [5]. The major advancement in understanding the nociceptive signaling came through the discovery of ion channels in this process [6], specifically vanilloid receptors (VR), also known as transient receptor potential vanilloid (TRPV) channels, involved in detecting temperature, chemical and inflammatory pain $[7,8]$.

Furthermore, recent advancement in molecular biology and completion of the human genome sequence has revealed the significance of protein kinases in maintaining normal cellular homeostasis and multiple disease pathology including their involvement in regulating neuronal plasticity and pain sensitization. Therefore,

*Corresponding author: Tej Kumar Pareek, PhD, Department of Pediatrics, Division of Pediatric Hematology and Oncology, University Hospitals Case Medical Center, Case Western Reserve University, 2013 Cornell Road, WRB-3501, Cleveland, OH 44106, Tel: 216-368-4994; Fax: 216-368-8919; E-mail: tkp5@case.edu

Received August 24, 2012; Accepted October 01, 2012; Published October 03 , 2012

Citation: Pareek TK, Zipp L, Letterio JJ (2012) Cdk5: An Emerging Kinase in Pain Signaling. Brain Disorders Ther S1:003. doi:10.4172/2168-975X.S1-003

Copyright: (c) 2012 Pareek TK, et al. This is an open-access article distributed under the terms of the Creative Commons Attribution License, which permits unrestricted use, distribution, and reproduction in any medium, provided the original author and source are credited. 
there is a growing interest in developing protein kinase inhibitors for the treatment of a number of diseases. More than 20 protein kinase inhibitors are already in clinical trials, and many others have entered in either clinical trial without their structure being disclosed or are still in preclinical studies [9]. Protein kinases are becoming the second largest group of drug targets after GPCRs, accounting for $20 \%-30 \%$ of drug discovery activity in many pharmaceutical companies. Although many protein kinase inhibitors are in clinical trials for treating different diseases, especially cancer, they are not specifically being tested for clinical pain. Here we will overview the involvement of protein kinases during pain signaling with specific focus on a newly emerging protein kinase, Cyclin-dependent kinase-5 (Cdk5) in this process.

\section{Cdk5 and its role in pain signaling}

The human genome encodes 518 protein kinases (constituting about $1.7 \%$ of all human genes), representing one of the largest protein families [10]. It is quite clear now that functionality of any protein in cell is determined by its post-translational modification, and kinases are the key fundamental enzymes involved in this process. Thus, the involvement and significance of kinases has been reported nearly in every cellular dynamic process including but not limited to metabolism, transcription, cell cycle, cytoskeletal rearrangement, apoptosis, cellular mobility and differentiation. Protein phosphorylation also plays a critical role in intercellular communication during development, in physiological responses, and in the proper functioning of the nervous and immune systems. Mutations and deregulation of protein kinases play causal roles in human disease, affording the possibility of developing agonists and antagonists of these enzymes for use in disease therapy $[9,11,12]$. Although protein kinases were not favored as targets for analgesics, studies in the last decade in various animal pain models [13] have demonstrated important roles of these kinases in regulating neuronal plasticity and pain sensitization following intense noxious stimuli and injuries. Both serine/threonine and tyrosine kinases have been reported to be involved in multiple aspects of pain signaling (Figure 1). Furthermore, protein kinases also play a central role in the short- and long lasting effects induced by opiates and other abused drugs, participating in the acquisition of tolerance, sensitization, and other behavioral hallmarks of drug addiction $[14,15]$.

\section{Cdk5 and pain; lessons from pharmacological inhibition and gene targeting}

Cdk5 is a unique member of the small proline-directed serine/ threonine kinase family. Initially misnamed due to its close sequential homology with other Cyclin-dependent kinase (Cdk) family member $\mathrm{Cdk} 2$, this kinase plays a limited role in cell cycle and has restricted association with cyclins. For a long period of time it has been thought that $\mathrm{Cdk} 5$ is mainly active in post-mitotic neurons due to the abundant and selective expression of its obligate partner proteins, p35 and p39 in these cells $[16,17]$. These notions about limited neuronal role and regulation of $\mathrm{Cdk} 5$ activity have been challenged however, by recent reports from Herrup et al., reporting its involvement in cell cycle, [18-21] indicating the regulation of Cdk5 by association with cyclin-I $[22,23]$. Moreover, a series of reports has been published from multiple research labs in the past few years, arguing the importance of this kinase beyond neurons [24-26]. Collectively, our current knowledge about this kinase suggests that in the central nervous system (CNS) normal Cdk5 activity is required for maintaining normal neuronal homeostasis and development whereas deregulated Cdk5 activity leads to neurodegenerative disorders [27-29]. In spite of the ubiquitous presence of Cdk5 protein, its activity in peripheral nervous system
(PNS) and non-neuronal tissues is hardly detected under normal conditions. However, the higher expression of Cdk5 and its activity are detected in these tissues under pathological conditions such as inflammation, cancer, diabetes etc., which coincides with upregulated p35 protein levels [24,26].

In 2006, we unraveled for the first time an unprecedented role of Cdk5 in PNS and showed its essential requirement in nociceptive pathway [30]. Since then, these results were further confirmed by several other research groups [31-37]. Essentially now it is well established that both Cdk5 and its activator p35 are present in dorsal root ganglion (DRG) and trigeminal ganglion (TG) and the expression and activity of Cdk5/p35 is increased upon nociceptive stimulation [30]. It has been reported that intrathecal administration of $\mathrm{Cdk} 5$ selective inhibitor, roscovitine not only attenuates formalin-induced nociceptive response but also diminishes morphine tolerance [38,39]. Based on these studies, a systemic evaluation of Cdk5 inhibitors on morphine induced analgesia and tolerance has been performed [40]. Analysis of the in vivo role of Cdk5 in pain signaling has been restricted due to the embryonic lethality of the Cdk5-knockout mice; however, it should be noted that Cdk5-knockout pups are unresponsive to noxious cutaneous pinch [41]. Moreover, genetically altered mice lacking p35 (p35-/-) or overexpressing p35 transgene (Tgp35) further validated the biological significance of this kinase, showing hypoalgesic and hyperalgesic behavior against heat and inflammatory pain, respectively [30]. As discussed above TRPV channels play an important role in pain signaling. We identified TRPV1 as a direct substrate for Cdk5/ p35 kinase [42]. Cdk5-mediated phosphorylation of TRPV1 at threonine-407 can modulate agonist-induced calcium influx, and this effect could be reversed by restoring Cdk5 activity. These results were further confirmed in primary nociceptor-specific Cdk5 conditionalknockout mice. These mice showed reduced TRPV1 phosphorylation, resulting in significant hypoalgesia and establishing the importance of Cdk5-mediated TRPV1 phosphorylation in its functional regulation specific to pain signaling [42]. The life span of these mice is not compromised however; these mice develop skin lesions upon aging due to general sensation loss, as evident from deep skin scratches that turn into unhealed wounds [43]. Further characterization of these mice showed that activity and expression of $\mathrm{Cdk} 5 / \mathrm{p} 35$ is restricted to $C$ fibers, and $A \beta$ and $A \delta$ fibers are spared with this kinase activity. This was also reflected in multiple pain testing where these mice showed significant altered response to heat, pain, inflammation and chemical induced hyperalgesia but not to mechanical stimuli.

\section{Role of Cdk5 in morphine tolerance and opioid addiction}

It is known that opioid analgesics are the most efficacious drugs used to relieve severe pain; however, chronic administration of these drugs can lead to the development of tolerance and dependence, processes that are intimately related to opioid addiction. The processes underlying opioid tolerance involve complex compensatory changes in many opioid and non-opioid neuronal circuits [44-46]. However, the molecular mechanisms underlying the development of morphine tolerance remain controversial. A growing body of literature suggests that $\mathrm{Cdk} 5 / \mathrm{p} 35$ plays an important role in opioid addiction and morphine tolerance. Both p35-/- (lacking Cdk5 activity $\approx 60 \%-70 \%$ lower than wild type) or Tgp35 (with higher Cdk5 activity $\approx 2-4$ fold higher than wild type) mice depict altered response towards morphine tolerance. More rapid development of morphine tolerance in Tgp35 mice suggests that hyperactivation of $\mathrm{Cdk} 5$ is an important factor in the development of tolerance [47]. Recently, it has been demonstrated 
that opioid addiction in humans and in rats is associated with neuronal $\mathrm{Cdk} 5 / \mathrm{p} 35$ levels, which cause aberrant hyperphosphorylation of NF-H proteins [48]. Cdk5/p35 and downstream signaling in the ventral striatum play a critical role in the effects of acute METH treatment as well as the development of behavioral METH sensitization [49]. Chronic morphine exposure upregulates the transcription factors cAMP response element binding protein (CREB) and $\delta$-fos $B$, both of which appear to partially mediate an aspect of tolerance [50,51]. $\delta$-fos $B$ is thought to be a sustained molecular switch for addiction [51]. Cdk5 is a downstream target gene of $\delta$ - $f \circ B$, and it regulates the effects of chronic cocaine exposure in mice [52,53]. Induction and/or activation of Cdk5 are also implicated in the development of psychological dependence on morphine [54]. As reported above, intrathecal roscovitine administration also prevents the development of morphine tolerance [39].

\section{Functional regulation and molecular involvement of Cdk5 during pain signaling}

It is quite clear that activity of Cdk5 is required to generate a nociceptive response; however, there is some ambiguity around the functional regulation of this kinase during pain signaling. It should be noted that during normal conditions the activity and expression of Cdk5/p35 is very low in DRG, TG or nociceptor nerve endings. This suggests that molecular activation specific to nociceptor sensation may lead to Cdk5/p35 activation. In order to better understand this process, multiple labs including ours have put significant efforts in identifying the upstream activators of $\mathrm{Cdk} 5 / \mathrm{p} 35$ during pain sensation. A systemic analysis of multiple predictors in this process revealed that tumor necrosis factor- $\alpha$ (TNF- $\alpha$ ) and transforming growth factor- $\beta$ (TGF- $\beta$ ) present in inflammatory soup and released during tissue injury, regulate Cdk 5 activity, by MAPKs through subsequent activation of Egr- 1 and p35 expression [33,55]. Once activated it regulates mitogen-activated protein kinase kinase $1 / 2$ (MEK1/2) activity through a negative feedback loop [47] and ensures the constitutive activation of MAPK pathway which further maintains higher activity of Cdk5/p35 during chronic pain. This upregulated Cdk5 activity leads to phosphorylation

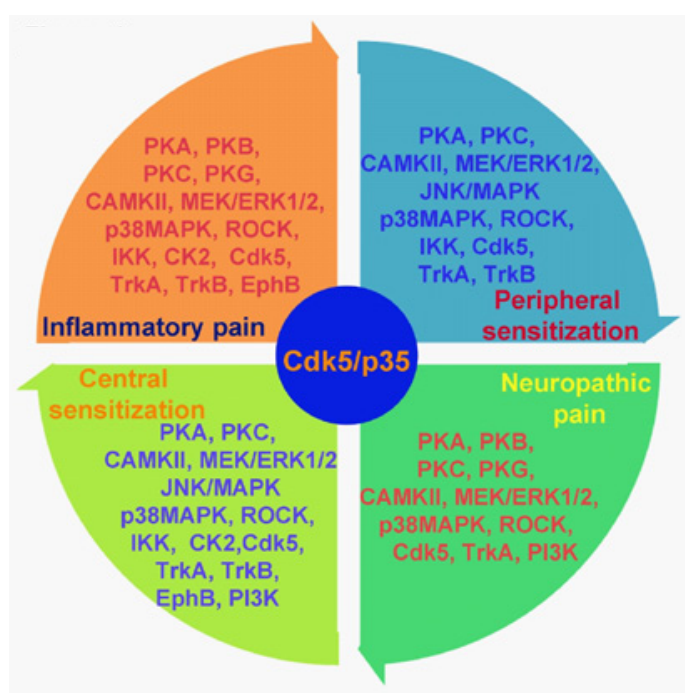

Figure 1: An overview of involvement of multiple protein kinases in different aspects of pain such as, peripheral sensitization, neuropathic pain, central sensitization and inflammatory pain. Cdk5/p35 signaling can directly or indirectly influence the activity of these kinases.

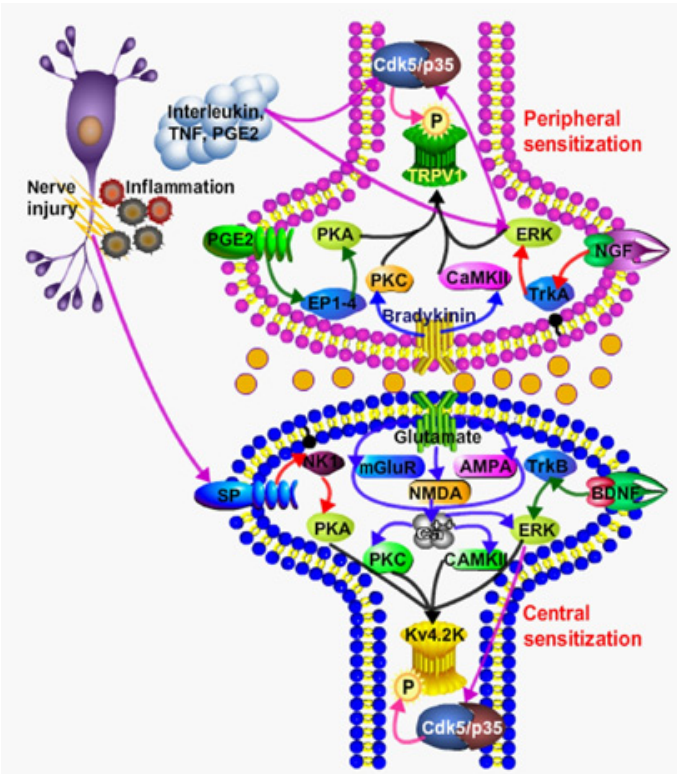

Figure 2: Molecular involvement of Cdk5/p35 during pain signaling: At the site of tissue injury immune cells get activated and release inflammatory soup which includes but not limited to interleukins, TNF PGE2, and NGF. These cytokines activate receptors on nociceptor terminals including TNFR, NGFR (TrkA) and PGE2 leading to the activation of other kinases such as PKA, PKC, CaMK-II, ERK. This process leads to further activation of Cdk5/p35. Activated Cdk5 leads to phosphorylation of TRPV1 and activates TRPV1 ion channel, causing peripheral sensitization. The central sensitization occurs indirectly via release of glutamate and/or neurotrophins from peripheral neurons or directly by the release of the substance $P$. Overall this process leads to the activation of NMDA, AMPA, mGluR and TrkB receptors by corresponding ligands and further activating downstream kinases such as PKA, PKC, CaMK-II, ERK. This process further activates the Cdk5/p35 in postsynaptic dorsal horn neurons which modulates the activity of other ion channels by their by posttranslational modification.

of Cdk5 targeted substrates such as TRPV1 [42], $\delta$-opioid receptor [56], $\mathrm{N}$-methyl-D-aspartate receptor (NMDAR) NR2B subunit [37,57], P/Q type voltage-dependent calcium channel [58] and ATP-gated P2X(3) receptors [59] and regulates their function.

For some time it has been recognized that inflammatory mediators released from immune cells can contribute to the persistent pathological pain states. However, it has only recently become clear that immune cell products might have a crucial role not just in inflammatory pain, but also in neuropathic pain caused by damage to peripheral nerves or to the CNS. The immune cells have an important role as pain modulators not just in inflamed tissues, but also in damaged peripheral nerves and in the CNS. The types of immune cells that contribute to inflammatory pain depend on the inflammatory condition, however, the role of mast cells, macrophages, $\mathrm{T}$ and $\mathrm{B}$ cells have been studied well in multiple experimental pain models [60]. These immune cells can act at many anatomical levels during pain sensation such as peripheral tissues that are undergoing inflammation, peripheral nerves and the spinal cord in cases of peripheral neuropathy. During inflammation a wide range of immune mediators is released from these cells, some of which can affect pain signaling systems. We have recently identified a crucial role for Cdk5/p35 in T cell activation and inflammation associated with autoimmune disorders such as multiple sclerosis [61]. It would be interesting to further explore the activity of this kinase in other immune cells as well as its functional involvement in immune cells during inflammatory pain. 


\section{Protein Kinases and their Plausible Interaction with Cdk5 during Pain Signaling}

A growing body of literature suggests that inflammatory mediators such as prostaglandin E2, serotonin, epinephrine, and nerve growth factor (NGF) produce hyperalgesia through activation of protein kinase $\mathrm{A}$ or C (PKA or PKC) in primary afferent neurons [62,63]. However, it has been shown that the ERK cascade acts in epinephrine-induced hyperalgesia and the Ras-MEK-ERK pathway is activated independently of PKA or PKC [64-66]. Activation of mitogen-activated protein kinase (MAPK) in nociceptive neurons leads to pain hypersensitivity through transcription-dependent and -independent means [67,68]. Activation of these kinases may directly or indirectly increase the transcription of various immediate early genes, including c-fos, Zif 268, and cyclooxygenase-2 (Cox-2), as well as other early response genes, which are thought to cause a transition from short-term adaptive processes to long-term hyperexcitability of nociceptive neurons, leading to the development of chronic pain [67-74]. Therefore, it is important to understand the relationship and potential crosstalk between Cdk5 and other kinases during pain signaling (Figure 2).

\section{PKA, PKC, and PKG}

For example, mice carrying a null mutation in neuronal-specific isoform of protein kinase A (PKA) subunit RI- $\beta$ are hyporesponsive to injury-induced inflammation and pain [75]. Moreover, prostaglandin $\mathrm{E}(2)$ (PGE(2)), a cyclooxygenase (COX) product, is the best known lipid mediator that acts through CAMP-PKA pathway to sensitize the peripheral terminals of nociceptors during inflammatory pain [76]. The involvement of PKA in mouse model of chemical and mechanical allodynia has also been reported [77,78]. Recent data suggest that activation of spinal T-cell death-associated gene-8 (TDAG8) contributes to bone cancer pain through the PKA signaling pathway in rats [79]. Sustained morphine mediated activation of spinal cAMP/ PKA dependent signaling also plays an important role in opioid induced hyperalgesia [80]. Interestingly, Cdk5 phosphorylates Thr75 of dopamine- and cAMP-regulated phosphoprotein of $32 \mathrm{kDa}$ (DARPP-32), which results in protein kinase A (PKA) inhibition [81]. This Cdk5 activity has been shown to regulate dopaminergic and glutamatergic signals, both of which are important in the molecular mechanisms of drugs of abuse including opiates [81]. Furthermore, retinoic acid treatment is shown to induce $c$-fos mediated AP- 1 binding, and cAMP-responsive element binding protein (CREB) mediated CRE binding via ERK1/2 and PKA pathway, respectively, in the Cdk5 promoter region, resulting in the induction of Cdk5 [82].

The involvement of protein kinase $\mathrm{C}$ (PKC) in analgesia and its importance in peripheral and central sensitization during chronic pain has been discussed at length by Velázquez et al. [83]. Mainly PKCe mediates peripheral sensitization whereas $\mathrm{PKC} \gamma$ plays important role in central sensitization. By phosphorylating key intermediates PKC enhances excitatory signaling and suppresses inhibitory signaling to reduce pain threshold and induce chronic pain $[84,85]$. It has been shown that PKC $\delta$ stabilizes the p35 protein level by phosphorylating p35 and diminishing its ubiquitination. Furthermore, $\mathrm{PKC} \delta$ can be activated by the brain-derived neurotrophic factor (BDNF) and is required for the activation of Cdk5 by BDNF [86]. Moreover it has been argued that PKC exerts its effects on the phosphorylation state of Cdk5 substrates through an indirect mechanism that may involve regulatory binding partners of Cdk5 other than its neuronal cofactors [87]. Mice lacking protein kinase G1 (PKG-1) show reduced inflammatory hyperalgesia with preservation of acute thermal nociception, suggesting the importance of this kinase in inflammatory pain [88].

\section{Calcium/calmodulin-dependent kinase-II (CaMKII)}

Up-regulation of calcium/calmodulin-dependent kinase-II (CaMKII) activity in the dorsal horn of spinal cord has been reported during both neuropathic pain and central sensitization [89,90]. Recent reports further validate the involvement of this kinase in pelvic, visceral and neuropathic pain [91-93]. CaMKII has also been recognized as a potential protein kinase, which by virtue of its co-localization with $\mu$-opioid receptor may be in a position to phosphorylate the $\mu$-opioid receptor and may thus contribute to the development of tolerance to opioid analgesics [94]. Studies from Tsai et al. [95], have revealed that alpha-actinin-1 and the alpha-subunit of $\mathrm{Ca}^{2+} /$ calmodulindependent protein kinase II (CaMKII- $\alpha$ ), two proteins localized at the postsynaptic density; interact with Cdk5 via their association with p35 and p39. CaMKII- $\alpha$ and $\alpha$-actinin- 1 bind to distinct regions of p 35 and p39 and also can interact with each other. Moreover, the association of CaMKII- $\alpha$ and $\alpha$-actinin- 1 to the Cdk5 activators, as well as to each other, is stimulated by calcium. Further, the activation of glutamate receptors increases the association of p35 and p39 with CaMKII- $\alpha$, and the inhibition of CaMKII activation diminishes this effect [95]. Moreover, Cdk5 activity is known to suppress CaMKII activation, and that the down regulation of Cdk5 activity after treatment with NMDA facilitates CaMKII activation, leading to the easier induction of longterm potentiation [96].

\section{Tropomyosin-related kinases (Trk)}

Tropomyosin-related kinases (Trks) are a family of receptor tyrosine kinases activated by neurotrophins. Trks play important roles in pain sensation as well as tumor cell growth and survival signaling. It's been shown that sustained administration of a peripherally selective Trk-A, $\mathrm{B}$ and $\mathrm{C}$ inhibitor significantly reduces skeletal pain without having any obvious detrimental effects on adult sensory and sympathetic nerve fibers [97]. Recently the potential and importance of several series of Trk inhibitors for the treatment of pain and/or cancer has been tested [98]. Neurotrophins such as NGF and BDNF enhance Cdk5 activity $[99,100]$. BDNF mediated activation of TrkB results in the recruitment of Cdk5 to the activated receptors, leading to phosphorylation of Cdk 5 by TrkB at Tyr15 [99], which has been demonstrated to enhance Cdk5 activity [101]. This finding reveals an alternative mechanism by which neurotrophins may elevate Cdk5 activity, although whether other Trk receptors similar to phosphorylate Cdk5 remains to be explored. TrkB was also identified as a substrate of Cdk5. Inhibition of TrkB phosphorylation by Cdk 5 abolishes BDNF-triggered increase in primary dendrites, in addition to attenuating BDNF-induced activation of Rho GTPase Cdc42, suggesting that phosphorylation of TrkB by Cdk5 is required for BDNF-induced dendrite growth [99]. Although the direct involvement of Cdk5 in Trk induced hyperalgesia has not been explored, it is intriguing to speculate that the inhibition of Cdk5 may abrupt neurotrophin triggered Trk signaling and thus dampen downstream nociceptive signaling cascade.

\section{MAPK and other kinases}

Increasing evidence indicates that mitogen-activated protein kinases (MAPKs), including extracellular signal-regulated kinase (ERK), p38, and c-Jun N-terminal kinase (JNK)-are involved in inflammatory and neuropathic pain. Central mechanisms of the MAPK family of signal transduction molecules have been well defined [102]. 
Translation of mRNA takes place in three steps, initiation, elongation, termination, and is a rapid and reversible process spatially controlled by a large number of upstream kinases [103]. In the periphery, the necessary machinery for the mRNA translation is present in peripheral sensory axons [104]. The available evidence implies that local mRNA translation can occur in primary afferents under the control of the mTOR and ERK pathways. One form of activated mTOR is restricted to A-nociceptors and a small subset of C-fibers that signal the secondary changes in sensitivity following injury while ERK modulated local protein synthesis regulates the sensitization of C-nociceptors by inflammatory mediators [105-108]. More recently, phosphorylated forms of ERK, p38, and JNK in primary afferent neurons have been shown to produce exaggerated pain sensation, suggesting that MAPK pathways can increase pain hypersensitivity via peripheral mechanisms [109-114]. Recent pharmacological studies showed differential roles of peripheral MAPK signal transduction pathways in different types of pain induced by inflammation [115,116]. For example, inhibitors of ERK, p38, and JNK have been shown to effectively alleviate inflammatory and neuropathic pain in different animal models. However, those specific MAPK pathway inhibitors, such as PD98059 and SB203580 are very useful reagents for basic research but cannot be used as drugs for reasons of toxicity, pharmacology, or solubility. It is also surprising to find that in several preclinical studies MEK inhibitors are well tolerated, given that the ERK cascade has been implicated in many cell functions including cell growth. It also remains to be tested whether these MAPK inhibitors are beneficial for patients with different pain conditions. IKK $\beta$-mediated NF- $\kappa B$ stimulation in injured primary sensory neurons promotes cytokine and chemokine production and contributes thereby to the development of chronic pain [117]. A novel and selective Rho kinase (ROCK) inhibitor AS1892802 has been shown to relieve pain symptoms in monoiodoacetate-induced arthritis and streptozotocininduced neuropathy pain models $[118,119]$. Casein kinase 2 (CK2) participates in inflammatory nociception both in the acute and chronic phases and the efficacy of a novel potent substituted pyrimido[4,5-c] quinoline ATP-competitive inhibitor of CK2 has been tested for pain therapy $[120,121]$. The role of PI3 kinase/AKT in pain signaling has also been shown in recent reports. Genetic deletion of PI3K $\gamma$ in mice enhanced scratching behaviors in histamine-dependent and proteaseactivated receptor 2 (PAR-2)-dependent itch [122]. Moreover, PI3kinase/Akt pathway has been shown to regulate membrane insertion of acid-sensing ion channel 1a (AISC1a) which underlies BDNF-induced pain hypersensitivity [123]. These findings emphasize, therefore, the importance of the mTOR and ERK pathways as a potential target for pain control. Interestingly, studies from Zheng et al. have revealed a crosstalk between Cdk5 and MAPK pathway [124,125]. Moreover, researchers have demonstrated that both the PI3K/Akt/mammalian target of rapamycin and the cdk5/p35 signal transduction pathways contribute to the induction of DARPP-32 protein levels by BDNF and that the effects are on both the transcriptional and translational levels. It also appears that PI3K is upstream of $\mathrm{cdk} 5 / \mathrm{p} 35$, and its activation can lead to an increase in p35 protein levels [126].

\section{Conclusion}

It is quite clear that there is an essential requirement for Cdk5/ p35 signaling to mount a nociceptive response. The importance of this kinase is not only linked to pain signaling but also involved in morphine tolerance and opioid addiction, providing a dominant focus for clinical analgesic therapy. The modulation of Cdk5/p35 activity in primary afferent neurons as well as in peripheral tissues makes it an attractive potential target for novel analgesics. Usually silent in PNS, this kinase gets activated upon nociceptive stimulation by transcriptional and translational regulation of both Cdk5 and p35. Once activated, Cdk5/ p35 not only interacts and regulates the activity of other protein kinases but also controls the functional regulation of multiple ion channels and other downstream signaling mediators involved in pain signaling. Past few years of research have made it clear that $\mathrm{Cdk} 5 / \mathrm{p} 35$ provides a fundamental mechanism of nociceptive regulation in an integrated network of communication among nociceptor terminals, their peripheral target tissues, and immune cells. Therefore, blocking Cdk5/ p35 activity might stop not only the initial peripheral events but also the later stages, when pain and inflammation manifests. The systemic efforts of multiple research labs involved in studying the role of Cdk5 in pain signaling put this kinase in the forefront of pain research and warrants the need of developing more specific and selective Cdk5 inhibitors and their use as pain analgesics, alone or in combination with other available pain relievers, particularly given the paucity of currently available pain medications.

\section{Reference}

1. Loeser JD (2012) Relieving pain in America. Clin J Pain 28: 185-186.

2. Perl ER (2007) Ideas about pain, a historical view. Nat Rev Neurosci 8: 71-80.

3. Hunt SP, Mantyh PW (2001) The molecular dynamics of pain control. Nat Rev Neurosci 2: 83-91.

4. Woolf CJ, Salter MW (2000) Neuronal plasticity: increasing the gain in pain Science 288: 1765-1769.

5. Basbaum Al, Bautista DM, Scherrer G, Julius D (2009) Cellular and molecular mechanisms of pain. Cell 139: 267-284

6. McCleskey EW, Gold MS (1999) Ion channels of nociception. Annu Rev Physio 61: 835-856

7. Caterina MJ, Rosen TA, Tominaga M, Brake AJ, Julius D (1999) A capsaicinreceptor homologue with a high threshold for noxious heat. Nature 398: 436441

8. Caterina MJ, Schumacher MA, Tominaga M, Rosen TA, Levine JD, et al. (1997) The capsaicin receptor: a heat-activated ion channel in the pain pathway. Nature 389: 816-824

9. Cohen $P$ (2002) Protein kinases--the major drug targets of the twenty-first century? Nat Rev Drug Discov 1: 309-315.

10. Manning G, Whyte DB, Martinez R, Hunter T, Sudarsanam S (2002) The protein kinase complement of the human genome. Science 298: 1912-1934.

11. Blume-Jensen P, Hunter $T$ (2001) Oncogenic kinase signalling. Nature 411 355-365.

12. Hunter T (2000) Signaling--2000 and beyond. Cell 100: 113-127.

13. Mogil JS (2009) Animal models of pain: progress and challenges. Nat Rev Neurosci 10: 283-294.

14. Christie MJ (2008) Cellular neuroadaptations to chronic opioids: tolerance, withdrawal and addiction. Br J Pharmacol 154: 384-396.

15. Lee AM, Messing RO (2008) Protein kinases and addiction. Ann N Y Acad Sci 1141: 22-57

16. Hellmich MR, Pant HC, Wada E, Battey JF (1992) Neuronal cdc2-like kinase: a cdc2-related protein kinase with predominantly neuronal expression. Proc Nat Acad Sci U S A 89: 10867-10871.

17. Tsai LH, Delalle I, Caviness VS Jr, Chae T, Harlow E (1994) p35 is a neuralspecific regulatory subunit of cyclin-dependent kinase 5 . Nature 371: 419-423.

18. Zhang J, Herrup K (2011) Nucleocytoplasmic Cdk5 is involved in neuronal cell cycle and death in post-mitotic neurons. Cell Cycle 10: 1208-1214.

19. Zhang J, Li H, Herrup K (2010) Cdk5 nuclear localization is p27-dependent in nerve cells: implications for cell cycle suppression and caspase- 3 activation. $J$ Biol Chem 285: 14052-14061.

20. Zhang J, Li H, Yabut O, Fitzpatrick H, D'Arcangelo G, et al. (2010) Cdk5 
suppresses the neuronal cell cycle by disrupting the E2F1-DP1 complex. J Neurosci 30: 5219-5228.

21. Zhang J, Li H, Zhou T, Zhou J, Herrup K (2012) Cdk5 levels oscillate during the neuronal cell cycle: Cdh1 ubiquitination triggers proteosome-dependent degradation during S-phase. J Biol Chem 287: 25985-25994.

22. Brinkkoetter PT, Olivier P, Wu JS, Henderson S, Krofft RD, et al. (2009) Cyclin I activates Cdk5 and regulates expression of $\mathrm{Bcl}-2$ and $\mathrm{Bcl}-\mathrm{XL}$ in postmitotic mouse cells. J Clin Invest 119: 3089-3101.

23. Taniguchi Y, Pippin JW, Hagmann H, Krofft RD, Chang AM, et al. (2012) Both cyclin I and p35 are required for maximal survival benefit of cyclin-dependent kinase 5 in kidney podocytes. Am J Physiol Renal Physiol 302: F1161-F1171.

24. Contreras-Vallejos E, Utreras E, Gonzalez-Billault C (2012) Going out of the brain: non-nervous system physiological and pathological functions of Cdk5. Cell Signal 24: 44-52

25. Lalioti V, Pulido D, Sandoval IV (2010) Cdk5, the multifunctional surveyor. Cell Cycle 9: 284-311.

26. Rosales JL, Lee KY (2006) Extraneuronal roles of cyclin-dependent kinase 5 . Bioessays 28: 1023-1034.

27. Cheung ZH, Ip NY (2012) Cdk5: a multifaceted kinase in neurodegenerative diseases. Trends Cell Biol 22: 169-175.

28. Dhavan R, Tsai LH (2001) A decade of CDK5. Nat Rev Mol Cell Biol 2: 749-759

29. Hisanaga S, Endo R (2010) Regulation and role of cyclin-dependent kinase activity in neuronal survival and death. J Neurochem 115: 1309-1321.

30. Pareek TK, Keller J, Kesavapany S, Pant HC, ladarola MJ, et al. (2006) Cyclindependent kinase 5 activity regulates pain signaling. Proc Natl Acad Sci U S A 103: 791-796.

31. Li W, Fang M, Cai XH (2010) Expression and activity of Cdk5/p35 in a rat mode of trigeminal neuropathic pain. Shanghai Kou Qiang Yi Xue 19: 545-548.

32. Peng HY, Chen GD, Tung KC, Lai CY, Hsien MC, et al. (2009) Colon mustard oil instillation induced cross-organ reflex sensitization on the pelvic-urethra reflex activity in rats. Pain 142: 75-88.

33. Utreras E, Futatsugi A, Pareek TK, Kulkarni AB (2009) Molecular Roles of Cdk5 in Pain Signaling. Drug Discov Today Ther Strateg 6: 105-111.

34. Utreras E, Futatsugi A, Rudrabhatla P, Keller J, ladarola MJ, et al. (2009) Tumor necrosis factor-alpha regulates cyclin-dependent kinase 5 activity during pain signaling through transcriptional activation of p35. J Biol Chem 284: 2275-2284.

35. Xie WY, He Y, Yang YR, Li YF, Kang K, et al. (2009) Disruption of Cdk5associated phosphorylation of residue threonine-161 of the delta-opioid receptor: impaired receptor function and attenuated morphine antinociceptive tolerance. J Neurosci 29: 3551-3564.

36. Yang YR, He Y, Zhang Y, Li Y, Li Y, et al. (2007) Activation of cyclin-dependent kinase $5(\mathrm{Cdk} 5)$ in primary sensory and dorsal horn neurons by peripheral inflammation contributes to heat hyperalgesia. Pain 127: 109-120.

37. Zhang R, Liu Y, Zhang J, Zheng Y, Gu X, et al. (2012) Intrathecal administration of roscovitine attenuates cancer pain and inhibits the expression of NMDA receptor 2B subunit mRNA. Pharmacol Biochem Behav 102: 139-145.

38. Wang CH, Chou WY, Hung KS, Jawan B, Lu CN, et al. (2005) Intrathecal administration of roscovitine inhibits Cdk5 activity and attenuates formalininduced nociceptive response in rats. Acta Pharmacol Sin 26: 46-50.

39. Wang CH, Lee TH, Tsai YJ, Liu JK, Chen YJ, et al. (2004) Intrathecal cdk5 inhibitor, roscovitine, attenuates morphine antinociceptive tolerance in rats. Acta Pharmacol Sin 25: 1027-1030.

40. Parkitna JR, Obara I, Wawrzczak-Bargiela A, Makuch W, Przewlocka B, et al. (2006) Effects of glycogen synthase kinase 3beta and cyclin-dependent kinase 5 inhibitors on morphine-induced analgesia and tolerance in rats. J Pharmacol Exp Ther 319: 832-839.

41. Fu AK, Ip FC, Fu WY, Cheung J, Wang JH, et al. (2005) Aberrant motor axon projection, acetylcholine receptor clustering, and neurotransmission in cyclindependent kinase 5 null mice. Proc Natl Acad Sci U S A 102: 15224-15229.

42. Pareek TK, Keller J, Kesavapany S, Agarwal N, Kuner R, et al. (2007) Cyclin-dependent kinase 5 modulates nociceptive signaling through direct phosphorylation of transient receptor potential vanilloid 1. Proc Natl Acad Sci U S A 104: 660-665.
43. Saikkonen B, Pareek TK, Agarwal N, Molinolo A, Kriete M, et al. (2008) Conditional deletion of cyclin-dependent kinase 5 in primary sensory neurons leads to atypical skin lesions. Cell Cycle 7: 750-753.

44. Ammon-Treiber S, Höllt V (2005) Morphine-induced changes of gene expression in the brain. Addict Biol 10: 81-89.

45. Basbaum Al (1995) Insights into the development of opioid tolerance. Pain 61 : 349-352.

46. Nestler EJ (1996) Under siege: The brain on opiates. Neuron 16: 897-900.

47. Pareek TK, Kulkarni AB (2006) Cdk5: a new player in pain signaling. Cell Cycle 5: 585-588.

48. Ferrer-Alcón M, La Harpe R, Guimón J, García-Sevilla JA(2003) Downregulation of neuronal cdk5/p35 in opioid addicts and opiate-treated rats: relation to neurofilament phosphorylation. Neuropsychopharmacology 28: 947-955.

49. Chen PC, Chen JC (2005) Enhanced Cdk5 activity and p35 translocation in the ventral striatum of acute and chronic methamphetamine-treated rats. Neuropsychopharmacology 30: 538-549.

50. Li X, Clark JD (1999) Morphine tolerance and transcription factor expression in mouse spinal cord tissue. Neurosci Lett 272: 79-82.

51. Nestler EJ, Barrot M, Self DW (2001) DeltaFosB: a sustained molecular switch for addiction. Proc Natl Acad Sci U S A 98: 11042-11046.

52. Bibb JA, Chen J, Taylor JR, Svenningsson P, Nishi A, et al. (2001) Effects of chronic exposure to cocaine are regulated by the neuronal protein Cdk5. Nature 410: 376-380.

53. Takahashi S, Ohshima T, Cho A, Sreenath T, ladarola MJ, et al. (2005) Increased activity of cyclin-dependent kinase 5 leads to attenuation of cocainemediated dopamine signaling. Proc Natl Acad Sci U S A 102: 1737-1742.

54. Narita M, Shibasaki M, Nagumo Y, Narita M, Yajima Y, et al. (2005) Implication of cyclin-dependent kinase 5 in the development of psychological dependence on and behavioral sensitization to morphine. J Neurochem 93: 1463-1468.

55. Utreras E, Keller J, Terse A, Prochazkova M, ladarola MJ, et al. (2012) Transforming growth factor- $\beta 1$ regulates Cdk5 activity in primary sensory neurons. J Biol Chem 287: 16917-16929.

56. Chen HJ, Xie WY, Hu F, Zhang Y, Wang J, et al. (2012) Disruption of $\delta$-opioid receptor phosphorylation at Threonine 161 attenuates morphine tolerance in rats with CFA-induced inflammatory hypersensitivity. Neurosci Bull 28: 182 192

57. Li BS, Sun MK, Zhang L, Takahashi S, Ma W, et al. (2001) Regulation of NMDA receptors by cyclin-dependent kinase-5. Proc Natl Acad Sci U S A 98: 12742 12747.

58. Tomizawa K, Ohta J, Matsushita M, Moriwaki A, Li ST, et al. (2002) Cdk5/p35 regulates neurotransmitter release through phosphorylation and downregulation of P/Q-type voltage-dependent calcium channel activity. J Neurosci 22: 25902597.

59. Nair A, Simonetti M, Fabbretti E, Nistri A (2010) The Cdk5 kinase downregulates ATP-gated ionotropic P2X3 receptor function via serine phosphorylation. Cell Mol Neurobiol 30: 505-509.

60. Marchand F, Perretti M, McMahon SB (2005) Role of the immune system in chronic pain. Nat Rev Neurosci 6: 521-532.

61. Pareek TK, Lam E, Zheng X, Askew D, Kulkarni AB, et al. (2010) Cyclindependent kinase 5 activity is required for $T$ cell activation and induction of experimental autoimmune encephalomyelitis. J Exp Med 207: 2507-2519.

62. Gold MS, Levine JD, Correa AM (1998) Modulation of TTX-R INa by PKC and PKA and their role in PGE2-induced sensitization of rat sensory neurons in vitro. J Neurosci 18: 10345-10355.

63. Khasar SG, Lin YH, Martin A, Dadgar J, McMahon T, et al (1999) A nove nociceptor signaling pathway revealed in protein kinase $\mathrm{C}$ epsilon mutant mice. Neuron 24: 253-260

64. Aley KO, Martin A, McMahon T, Mok J, Levine JD, et al. (2001) Nociceptor sensitization by extracellular signal-regulated kinases. J Neurosci 21: 69336939.

65. Dina OA, McCarter GC, de Coupade C, Levine JD (2003) Role of the sensory neuron cytoskeleton in second messenger signaling for inflammatory pain Neuron 39: 613-624. 
66. Olah Z, Karai L, ladarola MJ (2002) Protein kinase C(alpha) is required for vanilloid receptor 1 activation. Evidence for multiple signaling pathways. J Biol Chem 277: 35752-35759

67. Malik-Hall M, Dina OA, Levine JD (2005) Primary afferent nociceptor mechanisms mediating NGF-induced mechanical hyperalgesia. Eur J Neurosci 21: $3387-3394$

68. Obata K, Noguchi K (2004) MAPK activation in nociceptive neurons and pain hypersensitivity. Life Sci 74: 2643-2653.

69. Beiche F, Scheuerer S, Brune K, Geisslinger G, Goppelt-Struebe M (1996) Upregulation of cyclooxygenase-2 mRNA in the rat spinal cord following peripheral inflammation. FEBS Lett 390: 165-169.

70. Draisci G, ladarola MJ (1989) Temporal analysis of increases in c-fos preprodynorphin and preproenkephalin mRNAs in rat spinal cord. Brain Res Mol Brain Res 6: 31-37.

71. Dubner R, Ruda MA (1992) Activity-dependent neuronal plasticity following tissue injury and inflammation. Trends Neurosci 15: 96-103.

72. Ji RR, Zhang X, Wiesenfeld-Hallin Z, Hökfelt T (1994) Expression of neuropeptide $\mathrm{Y}$ and neuropeptide $\mathrm{Y}(\mathrm{Y} 1)$ receptor mRNA in rat spinal cord and dorsal root ganglia following peripheral tissue inflammation. J Neurosci 14: 6423-6434.

73. Mannion RJ, Costigan M, Decosterd I, Amaya F, Ma QP, et al. (1999) Neurotrophins: peripherally and centrally acting modulators of tactile stimulusinduced inflammatory pain hypersensitivity. Proc Natl Acad Sci U S A 96: 93859390.

74. McCarson KE, Krause JE (1994) NK-1 and NK-3 type tachykinin receptor mRNA expression in the rat spinal cord dorsal horn is increased during adjuvant or formalin-induced nociception. J Neurosci 14: 712-720.

75. Malmberg AB, Brandon EP, Idzerda RL, Liu H, McKnight GS, et al. (1997) Diminished inflammation and nociceptive pain with preservation of neuropathic pain in mice with a targeted mutation of the type I regulatory subunit of cAMPdependent protein kinase. J Neurosci 17: 7462-7470.

76. Kawabata A (2011) Prostaglandin E2 and pain--an update. Biol Pharm Bull 34: 1170-1173.

77. Coderre TJ, Yashpal K (1994) Intracellular messengers contributing to persistent nociception and hyperalgesia induced by L-glutamate and substance $\mathrm{P}$ in the rat formalin pain model. Eur J Neurosci 6: 1328-1334.

78. Sluka KA, Willis WD (1997) The effects of G-protein and protein kinase inhibitors on the behavioral responses of rats to intradermal injection of capsaicin. Pain 71: $165-178$.

79. Hang LH, Yang JP, Yin W, Wang LN, Guo F, et al. (2012) Activation of spina TDAG8 and its downstream PKA signaling pathway contribute to bone cancer pain in rats. Eur J Neurosci 36: 2107-2117.

80. Tumati S, Roeske WR, Largent-Milnes TM, Vanderah TW, Varga EV (2011) Intrathecal PKA-selective siRNA treatment blocks sustained morphinemediated pain sensitization and antinociceptive tolerance in rats. $\mathrm{J}$ Neurosci Methods 199: 62-68.

81. Yger M, Girault JA (2011) DARPP-32, Jack of All Trades... Master of Which? Front Behav Neurosci 5: 56

82. Lee JH, Kim KT (2004) Induction of cyclin-dependent kinase 5 and its activator p35 through the extracellular-signal-regulated kinase and protein kinase A pathways during retinoic-acid mediated neuronal differentiation in human neuroblastoma SK-N-BE (2)C cells. Journal of neurochemistry 91: 634-647.

83. Velázquez KT, Mohammad H, Sweitzer SM (2007) Protein kinase C in pain: involvement of multiple isoforms. Pharmacol Res 55: 578-589.

84. Bailey CP, Smith FL, Kelly E, Dewey WL, Henderson G (2006) How important is protein kinase $\mathrm{C}$ in mu-opioid receptor desensitization and morphine tolerance? Trends Pharmacol Sci 27: 558-565.

85. Mandadi S, Tominaga T, Numazaki M, Murayama N, Saito N, et al. (2006) Increased sensitivity of desensitized TRPV1 by PMA occurs through PKCepsilon-mediated phosphorylation at S800. Pain 123: 106-116.

86. Zhao CT, Li K, Li JT, Zheng W, Liang XJ, et al. (2009) PKCdelta regulates cortical radial migration by stabilizing the Cdk5 activator p35. Proc Natl Acad Sci U S A 106: 21353-21358.

87. Sahin B, Hawasli AH, Greene RW, Molkentin JD, Bibb JA (2008) Negative regulation of cyclin-dependent kinase 5 targets by protein kinase $\mathrm{C}$. Eur $\mathrm{J}$ Pharmacol 581: 270-275.

88. Tegeder I, Del Turco D, Schmidtko A, Sausbier M, Feil R, et al. (2004) Reduced inflammatory hyperalgesia with preservation of acute thermal nociception in mice lacking cGMP-dependent protein kinase I. Proc Natl Acad Sci U S A 101 3253-3257.

89. Fang L, Wu J, Lin Q, Willis WD (2002) Calcium-calmodulin-dependent protein kinase II contributes to spinal cord central sensitization. J Neurosci 22: 41964204.

90. Garry EM, Moss A, Delaney A, O'Neill F, Blakemore J, et al. (2003) Neuropathic sensitization of behavioral reflexes and spinal NMDA receptor/CaM kinase I interactions are disrupted in PSD-95 mutant mice. Curr Biol 13: 321-328.

91. Crown ED, Gwak YS, Ye Z, Yu Tan H, Johnson KM, et al. (2012) Calcium/ calmodulin dependent kinase II contributes to persistent central neuropathic pain following spinal cord injury. Pain 153: 710-721.

92. Li Y, Zhang X, Liu H, Cao Z, Chen S, et al. (2012) Phosphorylated CaMKII postsynaptic binding to NR2B subunits in the anterior cingulate cortex mediates visceral pain in visceral hypersensitive rats. J Neurochem 121: 662-671.

93. Yang W, Rudick CN, Hoxha E, Allsop SA, Dimitrakoff JD, et al. (2012) Ca(2+)/ calmodulin-dependent protein kinase II is associated with pelvic pain of neurogenic cystitis. Am J Physiol Renal Physiol 303: F350-F356.

94. Brüggemann I, Schulz S, Wiborny D, Höllt V (2000) Colocalization of the muopioid receptor and calcium/calmodulin-dependent kinase II in distinct painprocessing brain regions. Brain Res Mol Brain Res 85: 239-250.

95. Dhavan R, Greer PL, Morabito MA, Orlando LR, Tsai LH (2002) The cyclindependent kinase 5 activators p35 and p39 interact with the alpha-subunit of $\mathrm{Ca} 2+/$ calmodulin-dependent protein kinase II and alpha-actinin-1 in a calciumdependent manner. J Neurosci 22: 7879-7891.

96. Hosokawa T, Saito T, Asada A, Ohshima T, Itakura M, et al. (2006) Enhanced activation of $\mathrm{Ca} 2+/$ calmodulin-dependent protein kinase II upon downregulation of cyclin-dependent kinase 5-p35. J Neurosci Res 84: 747-754.

97. Ghilardi JR, Freeman KT, Jimenez-Andrade JM, Mantyh WG, Bloom AP, et al. (2011) Sustained blockade of neurotrophin receptors TrkA, TrkB and TrkC reduces non-malignant skeletal pain but not the maintenance of sensory and sympathetic nerve fibers. Bone 48: 389-398.

98. Wang T, Yu D, Lamb ML (2009) Trk kinase inhibitors as new treatments for cancer and pain. Expert Opin Ther Pat 19: 305-319.

99. Cheung ZH, Chin WH, Chen Y, Ng YP, Ip NY (2007) Cdk5 is involved in BDNFstimulated dendritic growth in hippocampal neurons. PLoS Biol 5: e63.

100. Tokuoka H, Saito T, Yorifuji H, Wei F, Kishimoto T, et al. (2000) Brain-derived neurotrophic factor-induced phosphorylation of neurofilament-H subunit in primary cultures of embryo rat cortical neurons. J Cell Sci 113: 1059-1068.

101.Zukerberg LR, Patrick GN, Nikolic M, Humbert S, Wu CL, et al. (2000) Cables links Cdk5 and c-Abl and facilitates Cdk5 tyrosine phosphorylation, kinase upregulation, and neurite outgrowth. Neuron 26: 633-646.

102. Ji RR, Gereau RW 4th, Malcangio M, Strichartz GR (2009) MAP kinase and pain. Brain Res Rev 60: 135-148.

103. Price TJ, Géranton SM (2009) Translating nociceptor sensitivity: the role of axonal protein synthesis in nociceptor physiology. Eur J Neurosci 29: 2253 2263

104. Piper M, Holt C (2004) RNA translation in axons. Annu Rev Cell Dev Biol 20 505-523.

105. Géranton SM, Jiménez-Díaz L, Torsney C, Tochiki KK, Stuart SA, et al. (2009) A rapamycin-sensitive signaling pathway is essential for the full expression of persistent pain states. J Neurosci 29: 15017-15027

106. Jimenez-Diaz L (2008) Local translation in primary afferent fibers regulates nociception. PLoS One 3: e1961.

107. Melemedjian OK, Asiedu MN, Tillu DV, Peebles KA, Yan J, et al. (2010) IL-6and NGF-induced rapid control of protein synthesis and nociceptive plasticity via convergent signaling to the elF4F complex. J Neurosci 30: 15113-15123.

108. Obara I, Tochiki KK, Géranton SM, Carr FB, Lumb BM, et al. (2011) Systemic inhibition of the mammalian target of rapamycin (mTOR) pathway reduces neuropathic pain in mice. Pain 152: 2582-2595. 
Citation: Pareek TK, Zipp L, Letterio JJ (2012) Cdk5: An Emerging Kinase in Pain Signaling. Brain Disorders Ther S1:003. doi:10.4172/2168-975X. S1-003

Page 8 of 8

109. Dai Y, Iwata K, Fukuoka T, Kondo E, Tokunaga A, et al. (2002) Phosphorylation of extracellular signal-regulated kinase in primary afferent neurons by noxious stimuli and its involvement in peripheral sensitization. J Neurosci 22: $7737-$ 7745 .

110. Ji RR, Samad TA, Jin SX, Schmoll R, Woolf CJ (2002) p38 MAPK activation by NGF in primary sensory neurons after inflammation increases TRPV1 levels and maintains heat hyperalgesia. Neuron 36: 57-68.

111. Jin SX, Zhuang ZY, Woolf CJ, Ji RR (2003) p38 mitogen-activated protein kinase is activated after a spinal nerve ligation in spinal cord microglia and dorsal root ganglion neurons and contributes to the generation of neuropathic pain. J Neurosci 23: 4017-4022.

112. Obata K, Yamanaka H, Dai Y, Tachibana T, Fukuoka T, et al. (2003) Differential activation of extracellular signal-regulated protein kinase in primary afferent neurons regulates brain-derived neurotrophic factor expression after peripheral inflammation and nerve injury. J Neurosci 23: 4117-4126.

113. Obata K, Yamanaka H, Kobayashi K, Dai Y, Mizushima T, et al. (2004) Role of mitogen-activated protein kinase activation in injured and intact primary afferent neurons for mechanical and heat hypersensitivity after spinal nerve ligation. J Neurosci 24: 10211-10222.

114. Zhuang ZY (2006) A peptide c-Jun N-terminal kinase (JNK) inhibitor blocks mechanical allodynia after spinal nerve ligation: respective roles of JNK activation in primary sensory neurons and spinal astrocytes for neuropathic pain development and maintenance. J Neurosci 26: 3551-3560.

115. Chen HS, He X, Qu F, Kang SM, Yu Y, et al. (2009) Differential roles of peripheral mitogen-activated protein kinase signal transduction pathways in bee venom-induced nociception and inflammation in conscious rats. J Pain 10: 201-207.

116. Hao J, Liu MG, Yu YQ, Cao FL, Li Z, et al. (2008) Roles of peripheral mitogenactivated protein kinases in melittin-induced nociception and hyperalgesia. Neuroscience 152: 1067-1075

117. Kanngiesser M, Häussler A, Myrczek T, Küsener N, Lim HY, et al. (2012) Inhibitor kappa B kinase beta dependent cytokine upregulation in nociceptive neurons contributes to nociceptive hypersensitivity after sciatic nerve injury. $J$ Pain 13: 485-497.

118. Yoshimi E, Kumakura F, Hatori C, Hamachi E, Iwashita A, et al. (2010) Antinociceptive effects of AS1892802, a novel Rho kinase inhibitor, in rat models of inflammatory and noninflammatory arthritis. J Pharmacol Exp Ther 334: 955-963.

119. Yoshimi E, Yamamoto H, Furuichi Y, Shimizu Y, Takeshita N (2010) Sustained analgesic effect of the Rho kinase inhibitor AS1892802 in rat models of chronic pain. J Pharmacol Sci 114: 119-122.

120.Li X, Shi X, Liang DY, Clark JD (2005) Spinal CK2 regulates nociceptive signaling in models of inflammatory pain. Pain 115: 182-190.

121. Pierre F, O'Brien SE, Haddach M, Bourbon P, Schwaebe MK, et al. (2011) Novel potent pyrimido[4,5-c]quinoline inhibitors of protein kinase CK2: SAR and preliminary assessment of their analgesic and anti-viral properties. Bioorg Med Chem Lett 21: 1687-1691.

122. Lee B, Descalzi G, Baek J, Kim JI, Lee HR, et al. (2011) Genetic enhancement of behavioral itch responses in mice lacking phosphoinositide 3-kinase- $y$ (PI3K y). Mol Pain 7: 96

123. Duan B, Liu DS, Huang Y, Zeng WZ, Wang X, et al. (2012) PI3-kinase/Akt pathway-regulated membrane insertion of acid-sensing ion channel 1a underlies BDNF-induced pain hypersensitivity. J Neurosci 32: 6351-6363.

124. Sharma P, Veeranna, Sharma M, Amin ND, Sihag RK, et al. (2002) Phosphorylation of MEK1 by cdk5/p35 down-regulates the mitogen-activated protein kinase pathway. J Biol Chem 277: 528-534.

125.Zheng YL, Li BS, Kanungo J, Kesavapany S, Amin N, et al. (2007) Cdk5 Modulation of mitogen-activated protein kinase signaling regulates neuronal survival. Mol Biol Cell 18: 404-413.

126. Bogush A, Pedrini S, Pelta-Heller J, Chan T, Yang Q, et al. (2007) AKT and CDK5/p35 mediate brain-derived neurotrophic factor induction of DARPP-32 in medium size spiny neurons in vitro. J Biol Chem 282: 7352-7359.

This article was originally published in a special issue, Cdk5 and Brain Disorders handled by Editor(s). Dr. Jyotshnabala Kanungo, National Center for Toxicological Research, USA 